\title{
ПЕРСОНАЛИИ
}

УДК 902(47)-057

\author{
И.П. Засецкая ${ }^{1}$, Л.С. Марсадолов ${ }^{1}$, А.А. Тишкин ${ }^{2}$ \\ ${ }^{1}$ Государственный Эрмитаж, Санкт-Петербург, Россия; \\ ${ }^{2}$ Алтайский государственный университет, Барнаул, Россия
}

\section{ПАМЯТИ Л.Л. БАРКОВОЙ (1928-2014)}

Статья посвящена памяти известного в России специалиста, старшего научного сотрудника отдела археологии Восточной Европы и Сибири Государственного Эрмитажа (Санкт-Петербург), хранителя и исследователя сибирских древностей Л.Л. Барковой. После окончания Ленинградского государственного университета Людмила Леонидовна в 1953 г. стала работать в Государственном Эрмитаже. Она участвовала в археологических экспедициях, являлась куратором многих, в том числе зарубежных, выставок, осуществляла просветительскую и другую деятельность. Особое значение имеет ее вклад в обработку, изучение и хранение уникальных материалов, полученных при раскопках «царских» курганов скифо-сакского времени на Алтае, которые относятся к пазырыкской культуре. На эту тему Л.Л. Барковой написан ряд научных трудов. Особое значение имеют работы, посвященные древнему искусству. Сведения о состоявшихся публикациях представлены в виде библиографического списка, подготовленного коллегами. Они наиболее полно отражены в приложении к данной статье. Все, кто взаимодействовал с Людмилой Леонидовной, отмечают ее человеческие качества, а также высокий профессионализм и ответственное отношение к делу.

Ключевые слова: Государственный Эрмитаж, хранитель, искусство кочевников, пазырыкские древности, коллекция, выставка, экспонаты, научные публикации, каталог, Алтай, Сибирь.

DOI: $10.14258 /$ tpai(2016)1(13).-10

Л.Л. Баркова родилась 25 декабря 1928 г. в городке Кача, под Севастополем, в семье военнослужащего. Ее отец, Леонид Васильевич Барков, родом из города Ливны (Орловская область) - там он учился и работал на чугунно-литейном заводе. В 1924 г. Л.В. Баркова призвали в армию, где он служил до 1947 г. После ухода в запас устроился в Гидрологический институт инженером по приборам (скончался в 1972 г.). Мать, Га-

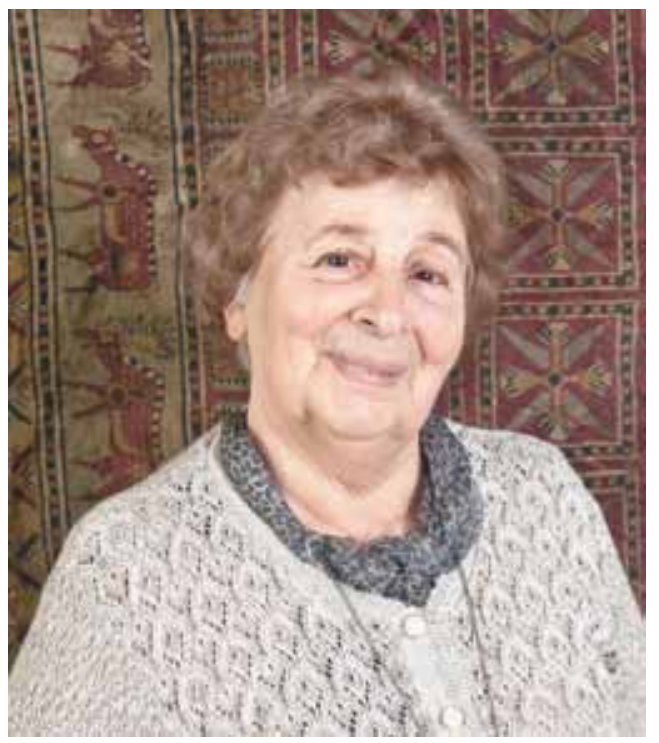

лина Андреевна (девичья фамилия Кроникова), родилась в 1908 г. в г. Вильно (ныне Вильнюс - столица Литвы). В 1909 г. семья переехала в Минск. После окончания школы Галина Андреевна получила профессию швеи. В 1929 г. вышла замуж и всю оставшуюся жизнь была домохозяйкой (умерла в 1952 г.). Младшая сестра, Светлана Леонидовна (Смирнова), родилась в 1932 г. После окончания института она работала преподавателем и переводчицей с иностранных языков.

Еще восьмимесячным ребенком Людмила вместе с семьей переехала в Ленинград, где и проживала до последних дней своей жизни, а потому была вправе считать себя коренной ленинградкой. В 1936 г. она 
пошла в школу №50 Петроградского района. Как и многие дети Великой Отечественной войны 1941-1945 гг., прошла сквозь все тягости и горести военных лет. С начала войны до середины 1942 г. Людмила с мамой и младшей сестрой, следуя за воинской частью, где служил их отец, переезжала с места на место, меняя адреса. И только в 1942 г. с последним эшелоном, увозившим актеров и имущество Мариинского театра, они эвакуировались в Среднюю Азию. В 1943 г. она вступила в комсомол, затем по возрасту выбыла и в дальнейшем была беспартийным человеком. В 1944 г. в связи с тем, что отец был переведен из действующей армии в г. Львов, мать с детьми переехали туда.

После окончания войны в 1946 г. семья перебралась Казань, где Людмила закончила среднюю школу. В 1947 г. все вернулись в Ленинград.

В 1947-1952 гг. Л.Л. Баркова училась в Ленинградском государственном университете им. А.А. Жданова на кафедре археологии исторического факультета. Во время учебы она также была шефом в ремесленном училище и агитатором во время избирательных кампаний. Еще в университете и в летних экспедициях завязалась крепкая дружба трех подруг (будущих хранителей Эрмитажа) - Л.К. Галаниной, И.П. Засецкой и Л.Л. Барковой, которую они пронесли через всю жизнь. Хорошую практическую археологическую подготовку Л.Л. Баркова получила в течение трех лет, работая в составе Волго-Донской экспедиции, а также на однолетней практике в Старой Ладоге. Людмила Леонидовна специализировалась по археологии и написала дипломную работу на тему «Заселение славянами Подонья (по археологическим данным Волго-Донской экспедиции)» под руководством профессора Л.А. Мацулевича.

На работу в Государственный Эрмитаж, в отдел истории первобытной культуры (ОИПК), Л.Л. Баркову в марте 1953 г. принял директор музея М.И. Артамонов, у которого еще в студенческие годы она слушала лекции и работала в археологической экспедиции на Дону. Сначала два года (1953-1955 гг.) Людмила Леонидовна работала научно-техническим сотрудником в ОИПК, а затем с 1955 по 1962 г. была переведена экскурсоводом в научно-просветительный отдел (НПО). Она всегда легко находила общий язык с людьми и умела расположить к себе слушателей, была членом общества «Знание», проводила экскурсии, читала лекции в Эрмитаже и за его пределами, делала это эмоционально и с удовольствием.

В 1950-е гг. Людмила Леонидовна познакомилась с известным археологом Михаилом Петровичем Грязновым, в археологических экспедициях которого неоднократно участвовала в Хакасии и Туве, в том числе и на раскопках знаменитого кургана Аржан-1. М.П. Грязнов помог Л.Л. Барковой стать хранителем коллекций из больших алтайских курганов. После возвращения в 1963 г. в отдел археологии Людмила Леонидовна работала там сначала научным, а с 1974 г. старшим научным сотрудником, до своего последнего дня в 2014 г.

Л.Л. Баркова хранила материалы с территории Западной Сибири, Казахстана и Алтая от эпохи бронзы до средневековья - более 150 коллекций, насчитывающих 15,5 тысяч инвентарных номеров. Она была хранителем алтайских древностей, одним из самых сложных собраний в музее, представленным редкими экспонатами из органических материалов - войлока, кожи, шерсти и дерева, которые постоянно требовали особого, тщательного и постоянного ухода, добросовестно и с любовью обеспечиваемого Людмилой Леонидовной с помощью реставраторов музея. Частично из своего большого хранения она передала коллекции Л.С. Марсадолову, С.В. Панковой и Е.В. Степановой. 
Л.Л. Баркова не только заботливо хранила уникальные коллекции из древних курганов Горного Алтая, но и продолжала свою просветительскую работу, увлекательно рассказывая посетителям о знаменитых находках. Кроме этого, она занималась научным изучением имеющихся материалов. Результаты такой деятельности нашли отражение в публикациях (см. список научных трудов). Следует отдельно отметить три статьи, в которых Людмила Леонидовна представила материалы большого кургана Шибе, раскопанного М.П. Грязновым еще в 1927 г. [Баркова, 1978, 1979, 1980]. В них подробно и тщательно был рассмотрен погребальный обряд, описаны все находки из кургана и указан антропологический тип «шибинца». Особое внимание уделено датировке исследованного объекта. Л.Л. Баркова сделала вывод, что курган Шибе не может служить основанием для выделения особого (шибинского) этапа в периодизации культуры ранних кочевников Алтая, и отметила, что он наиболее близок к кургану №3 памятника Пазырык и может быть датирован V-IV вв. до н.э. Эта дата являлась близкой к ранее опубликованной С.И. Руденко, хотя М.П. Грязнов определял Шибинский курган и выделенный им этап II в. до н.э. - І в. н.э. Три монографии С.И. Руденко [1953, 1960, 1968], посвященные материалам из больших курганов Алтая, постоянно были настольными книгами у Л.Л. Барковой, которая также опубликовала серию статей, посвященных предметам искусства кочевников Горного Алтая скифского времени, представленным изображениями в зверином стиле. Кроме того, Людмила Леонидовна совместно с С.В. Панковой принимала участие в исследовании древних татуировок на пазырыкских мумиях, что в октябре 2004 г. привело к открытию и публикации ранее не известных рисунков-татуировок.

В последние годы Людмила Леонидовна особое внимание уделяла изучению техники производства, а также декоративному оформлению войлочных и ворсовых шерстяных ковров. Результаты исследований этой группы находок были опубликованы ею в ряде статей, а также в монографии в соавторстве с Н.В. Полосьмак (Новосибирск, 2005 г.) и в научно-популярной книге, изданной в Государственном Эрмитаже в 2012 г. Совместно с одним из авторов данного очерка Л.Л. Баркова подготовила к печати пока не изданный каталог коллекции №1122, в которой отложились предметы из собрания П.К. Фролова. В ходе этой работы проанализирован существенный по объему разновременный археологический и другой материал, подготовлены многочисленные иллюстрации.

Нельзя не упомянуть о постоянном участии Людмилы Леонидовны в экспозиционной работе, подготовке и сопровождении временных международных выставок, в которых значительную часть экспонатов представляли алтайские древности. Л.Л. Баркова сопровождала выставки Государственного Эрмитажа в Японию, Югославию, США, Францию, Болгарию, Великобританию, Грецию и в другие страны. В качестве туриста была в Венгрии и Румынии. В каждом каталоге можно найти написанные ею пояснительные тексты к отдельным предметам и статьи, посвященные истории изучения горно-алтайских памятников.

Научную смелость в своих убеждениях Л.Л. Баркова проявила в 2009 г., когда готовилась новая экспозиция для постоянной музейной выставки «Древняя Сибирь». Более молодые сотрудники Государственного Эрмитажа хотели обозначить на этикетках даты для Туэкты-1 и Башадара-2 - V-IV вв. до н.э., а для Пазырыка - 
IV-III вв. до н.э., но Людмила Леонидовна как хранитель материалов из этих комплексов твердо настояла на датах VI-V вв. до н.э. (для Туэкты/Башадара) и V-IV вв. до н.э. (для Пазырыка).

Л.Л. Баркова была замужем за известным антропологом И.И. Гохманом (19282008 гг.), заведующим отделом Института антропологии и этнографии РАН, который консультировал супругу по многим вопросам и был соавтором совместных научных статей.

Ряд хороших рисунков к публикациям Л.Л. Барковой выполнил ее друг - замечательный художник-график и живописец Е.С. Матвеев.

Редко упоминают еще одно важное занятие хранителей музея - обслуживание посетителей: показ материала в хранилищах и на экспозициях, научные консультации, включающие сведения по истории формирования коллекций и их исследованию. И здесь на долю Людмилы Леонидовны выпал немалый объем работы, поскольку находки из больших алтайских курганов скифского времени имеют мировую известность и поэтому всегда востребованы. Сотрудники многих музеев и научных институтов (археологи, историки, искусствоведы из разных регионов нашей страны), а также иностранные коллеги были ее нередкими гостями. Более того, она не только осуществляла свои прямые обязанности хранителя, показывая музейные коллекции, но и доброжелательно проявляла искреннюю заботу о своих посетителях. Ее гостеприимство, веселость и отзывчивость проявлялись не только по отношению к родным и близким друзьям, но и к коллегам и просто знакомым, к людям и животным, которые нуждались в искреннем сочувствии, помощи и поддержке.

За многолетнюю добросовестную работу в музее Л.Л. Баркова неоднократно награждалась почетными грамотами и ценными подарками. Она награждена знаком «Победитель социалистического соревнования 1977 г.» и медалью «Ветеран труда» в 1986 г. Свою последнюю грамоту - «Благодарность Министра культуры РФ», подписанную В.Р. Мединским 18 февраля 2014 г., - она так и не успела лично получить.

Большим событием в жизни Людмилы Леонидовны был ее 85-летний юбилей, который она вместе с коллегами отдела археологии и приглашенными гостями отмечала 26 февраля 2014 г. Но через 10 дней ее не стало... На юбилее, на прощании и поминках было много гостей, много добрых и искренних выступлений, так как в музее Людмила Леонидовна пользовалась заслуженным уважением и любовью, проработав там 61(!) год.

Память о Людмиле Леонидовне Барковой будет долго и бережно храниться в сердцах всех знавших ее друзей и коллег.

\section{Библиографический список}

Баркова Л.Л. Курган Шибе и вопросы его датировки // Археологический сборник ГЭ. 1978. Вып. 19. С. 37-44.

Баркова Л.Л. Погребение коней в кургане Шибе // Археологический сборник ГЭ. 1979. Вып. 20. C. 55-65.

Баркова Л.Л. Курган Шибе. Предметы материальной культуры из погребальной камеры // Археологический сборник ГЭ. 1980. Вып. 21. С. 48-58.

Руденко С.И. Культура населения Горного Алтая в скифское время. М. ; Л. : Изд-во АН СССР, 1953. $402 \mathrm{c}$.

Руденко С.И. Культура населения Центрального Алтая в скифское время. М. ; Л. : Изд-во АН CСCР, 1960. 360 с. + CXXVI табл.

Руденко С.И. Древнейшие в мире художественные ковры и ткани из оледенелых курганов Горного Алтая. М. : Искусство, 1968. 136 с. 


\section{I.P. Zasetskaya, L.S. Marsadolov, A.A. Tishkin IN MEMORY OF L.L. BARKOVA (1928-2014)}

The article is devoted to L.L. Barkova - the famous Russian expert, the senior researcher of the department of Archaeology of Eastern Europe and Siberia of the State Hermitage (St. Petersburg), the keeper and the researcher of Siberian antiquities. After the graduation from the Leningrad State University, Lyudmila Leonidovna began to work in the State Hermitage in 1953. She participated in archaeological expeditions, was a curator of many exhibitions, including foreign ones, carried out educational and other activities. Her contribution to processing, studying and storage of the unique materials received at excavation of "imperial" barrows of Scythian-Saka time in Altai which belong to Pazyryk culture have a particular importance. L.L. Barkova wrote a number of scientific works on the subject. The papers devoted to ancient art have a special value. The information on the publications prepared by her colleagues is presented in the form of the bibliography. It is presented in the supplement to the article. All who interacted with Lyudmila Leonidovna note her human qualities, high professionalism and a responsible attitude to work.

Key words: State Hermitage, keeper, art of nomads, Pazyryk antiquities, collection, exhibition, exhibits, scientific publications, catalog, Altai, Siberia.

\section{References}

Barkova L.L. Kurgan Shibe i voprosy ego datirovki [The Shibe mound and the questions of its dating]. Arkheologicheskiy sbornik Gosudarstvennogo Ermitazha [Archaeological collection of the State Hermitage], 19, 1978. Pp. 37-44.

Barkova L.L. Kurgan Shibe. Predmety material'noy kul'tury iz pogrebal'noy kamery [Kurgan Shibe and the objects of the material culture from the burial chanber]. Arkheologicheskiy sbornik Gosudarstvennogo Ermitazha [Archaeological collection of the State Hermitage], 21, 1980. Pp. 48-59.

Barkova L.L. Pogrebenie koney v kurgane Shibe [The burials of horses in the Shiba mound]. Arkheologicheskiy sbornik Gosudarstvennogo Ermitazha [Archaeological collection of the State Hermitage], 20, 1979. Pp. 55-65.

Rudenko S.I. Drevneyshie v mire khudozhestvennye kovry i tkani iz oledenelykh kurganov Gornogo Altaya [The oldest in the world art carpets and fabrics from the icy mounds of the Altai Mountains]. Moscow : Iskusstvo, 1968. $136 \mathrm{p}$.

Rudenko S.I. Kul'tura naseleniya Gornogo Altaya v skifskoe vremya [The culture of the population of the Altai Moiuntains in the Scythian time]. Mosvow ; Leningrad : Izd-vo AN SSSR, 1953. 402 p.

Rudenko S.I. Kul'tura naseleniya Tsentralnogo Altaya v skifskoe vremya [The culture of the Central Altai population in the Scythian time]. Moscow ; Leningrad : Izd-vo AN SSSR, 1960. 360 p. + CXXVI tabl.

\section{Список научных работ Л.Л. Барковой}

1. Алтайские курганы: Выставка «Культура и искусство древнего населения Сибири»: Краткий путеводитель. Государственный Эрмитаж. Л. : Аврора, 1973. 26 с. : ил.

2. Культура и искусство древнего населения Сибири: [Экспозиция] // Сообщения ГЭ. 1974. №39. С. 77-78 : ил. (в соавторстве с М.П. Завитухиной).

3. Таштыкский могильник Барсучиха-ІІ // Первобытная археология Сибири. Л. : Наука, 1974. С. 165-173 : ил.

4. Древняя Сибирь: Путеводитель по выставке «Культура и искусство древнего населения Сибири: VII в. до н.э. - ХІІІ в. н.э.». Государственный Эрмитаж. Л. : Аврора, 1976. 136 с. : ил., карт. (в соавторстве с М.П. Завитухиной, М.Б. Щукиным).

5. Złoto scytyjskie: [Katalog]. Warszawa, 1976 (в соавторстве с Л.К. Галаниной).

6. Злато Скита из музејских ризница СССР-а. Београд : Народи музеј, 1977. 62 с. : 15 л. ил. (в соавторстве с Л.К. Галаниной).

7. Arte della Siberia e dell'Altaj, VI-II sec. A.C. // L'Oro degli Sciti. [Catalogo]. Venezia, 1977. C. 45-77. 
8. Курган Шибе и вопросы его датировки // Археологический сборник ГЭ. 1978. Вып. 19. С. 37-44 : ил.; рез. англ.

9. Frozen Tombs: The Culture and Art of theancient Tribes of Siberia: [Catalogie]. London : British Museum, 1978. 102 p. : ill. (в соавторстве с М.П. Завитухиной).

10. Погребения коней в кургане Шибе // Архелогический сборник ГЭ. 1979. Вып. 20. С. 55-65 : ил.; рез. англ.

11. Arte de Siberia y de Altai, siglos VI-II a. C. // El Oro de los Escitas. Mexico, 1979. P. 48-81.

12. Курган Шибе: Предметы материальной культуры из погребальной камеры // Археологический сборник ГЭ. 1980. Вып. 21. С. 48-58 : ил.; рез. англ.

13. Великобритания: «Культура и искусство древних племен Сибири»: [Выставка] // Сообщения ГЭ. 1981. №46. С. 77-78. (в соавторстве с М.П. Завитухиной).

14. Изображение на саркофаге из второго Башадарского кургана: К вопросу о переднеазиатских элементах в искусстве древнего Алтая) // Контакты и взаимодействия древних культур : тезисы докладов научной конференции. Л., 1981. С. 14-15.

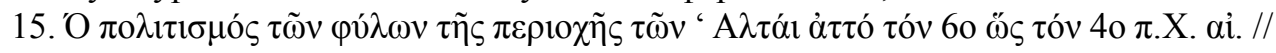

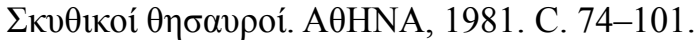

16. Изображения свернувшихся хищников на золотых пластинах из Майэмира // Археологический сборник ГЭ. 1983. Вып. 24. С. 20-31 : ил.; рез. англ.

17. В.П. Полторацкая (1899-1980): [Некролог] // Сообщения ГЭ. 1983. №48. С. 72 (в соавторстве с М.П. Завитухиной).

18. Резные изображения животных на саркофаге из 2-го Башадарского кургана // Археологический сборник ГЭ. 1984. Вып. 25. С. 83-89 ; рез. англ.

19. Die Kultur der Altai-Nomaden von 6. bis zum 4. Jahrhundert v. Chr.: Funde aus den Kurganen von Tueka, Basadar und Pazyryk // Gold der Skythen aus der Leningrader Eremitage. München, 1984. P. 164-218.

20. Изображения рогатых и крылатых тигров в искусстве древнего Алтая // Археологический сборник ГЭ. 1985. Вып. 26. С. 30-44 : ил; рез. англ.

21. Az Altáji Törzsek kultúrája az I. E. VI-IV. században. // Szkiták aranya. A leningrádi Ermitázs vendégkiállitása. Budapest, 1985. C. 34-43.

22. Конская маска из Первого Пазырыкского кургана // Исторические чтения памяти М.П. Грязнова : тезисы докладов. Ч. 2. Омск, 1987. С. 89-71.

23. М.П. Грязнов (1902-1984) [Некролог] // Сообщения ГЭ. 1987. №52. С. 96-97 (в соавторстве с Л.С. Марсадоловым).

24. Образ орлиноголового грифона в искусстве древнего Алтая: (По материалам Больших Алтайских курганов) // Археологический сборник ГЭ. 1987. Вып. 28. С. 5-29 : ил.; рез. англ.

25. Collezione delle antichitá degli Altai del VI-IV secolo a. c. // Tesori D’Eurasia. 2000 anni di Storia in 70 anni di Archeologia Sovetica. Milano, 1987. P. 89-111.

26. Die Kultur der Altai-Nomaden von 6. bis zum 4. Jahrhundert v. Chr.: Funde aus den Kurganen von Tueka, Bašadar und Pazyryk // Gold der Skythen aus der Leningrader Eremitage. Wien, 1988. P. 164-212.

27. Эрмитаж. (Альбом-путеводитель) Т. 4. Japan, Hiroyiki Itsuki NHK, 1989. C. $43-47$.

28. Образ оленя в искусстве древнего Алтая (по материалам Больших Алтайских курганов) // Археологический сборник ГЭ. 1990. Вып. 30. С. 55-60 : ил.; рез. англ. 
29. Изображение человека в искусстве древнего Алтая (по материалам Больших Алтайских курганов) // Археологические культуры Евразии : тезисы докладов научной конференции. СПб., 1991. С. 13-15.

30. La civilisation des nomades de l'Altaï du VI ${ }^{\mathrm{e}}$ au IV ${ }^{\mathrm{e}}$ siècle avant J.-C. Dècouvertes des kourganes de Touekta, Bachadar et Pazyryk // L'or des Scythes. Trésors de 1'Ermitage, Leningrad. Bruxelles, 1991. P. 166-215.

31. The Scythian gold from the Hermitage. Seul, 1991. Р. 180-235.

32. Происхождение ранних кочевников Алтая в свете данных палеоантропологии и анализа их изображений // Элитные курганы степей Евразии в скифо-сарматскую эпоху. СПб., 1994. С. 24-35 : ил. (в соавторстве с И.И. Гохманом).

33. Die Kultur der Altai-Nomaden von 6. bis zum 4. Jahrhundert v. Chr.: Funde aus den Kurganen von Tueka, Bašadar und Pazyryk // Gold der Skythen. Schätze aus der Staatlichen Eremitage St. Petersburg. Hamburg, 1993. P. 166-215.

34. De beschaving van de Altaïsche stammen van de 7de tot de 3 de eeuw v. Chr // Het rijk der scythen. Amsterdam, 1993. P. 74-101.

35. Antiquities from the Pazyryk Burial Mounds // The State Hermitage. Masterpieces from the Museum's Collections. Vol. 1. London, 1994. P. 110-123.

36. О хронологии и локальных различиях в изображении травоядных хищников в искусстве ранних кочевников Алтая: (опыт статистического анализа) // Археологический сборник ГЭ. 1995. Вып. 32. С. 60-76 : ил.; рез. англ.

37. The Altai culture. (exhb.: Natijnal Museum of Korea). Seul, 1995.

38. Мумии человека из погребений Пазырыкских курганов: (Алтай, сер. I тыс. до н.э.) // Актуальные вопросы антропологии : тезисы докладов. СПб., 1996. С. 25-26.

39. Le tapis de laine du kourgane №5 de Pazyryk // Dossiers d'Archeologie. 1996. №212. S. 2-27 : ill.

40. А.Д. Мачинская: 1964-1994: [Некролог] // Сообщения ГЭ. 1997. №57. С. 143 : портр.

41. Die skythenzeitliche Archäologie des Altai-Gebiets // Zwei Gesichter der Eremitage. Die Scythen und ihr Gold. Band I. Bonn, 1997. P. 59-65.

42. Баркова Л.Л. Большой войлочный ковер из пятого Пазырыкского кургана // Древние культуры Центральной Азии и Санкт-Петербург : материалы Всерос. науч. конф., посвящ. 70-летию со дня рождения А.Д. Грача. СПб., 1998. С. 137-142 : ил.

43. Конская маска из первого Пазырыкского кургана // Археологический сборник ГЭ. 1999. Вып. 34. С. 97-101 : ил.; рез. англ.

44. Мы «первобытники» помним его: [Латынин Б.А.] // Судьба ученого. СПб., 2000. C. 131-132.

45. The Nomadic Culture of the Altai and the Animal Style // The golden Deer of Eurasia. New York, 2000. P. 241-247 : ill.

46. The Pazyryk Felts // Hali: carpet, textile and Islamic art; №113. Hali, 2000. P. 74-79.

47. The Nomadic Culture of the Altai and the Animal Style // The golden deer of Eurasia. Scythian and Sarmatian treasures from the Russian steppes. New York, 2000. P. 241-275.

48. Еще раз о мумиях человека из Пазырыкских курганов // Археологический сборник ГЭ. 2001. Вып. 78-90 : ил.; рез. англ. (в соавторстве с И.И. Гохманом).

49. Культура кочевников Алтая и искусство звериного стиля // Золотые олени Евразии : каталог выставки. СПб., 2001. С. 204-231 : ил. 
50. La cultura nomadica dell'Altaj lo stile animalistico // Oro. Il mistero dei sarmati e degli sciti. Milano, 2001. S. 52-56, 62-80 : ill.

51. La cultura dei nomadi dell'Altaj // Siberia: Gli uomini dei fiumi ghiaccati. Milano, Trieste, 2001. S. 27-30 : ill.

52. Le mummie umane dei kurgan di Pazyryk // Siberia: Gli uomini dei fiumi ghiaccati. Milano, Trieste, 2001. S. 51-57 : ill.

53. Prehistoric Old World Scalping: New Cases from Cemetery of Aymyrlyg, South Siberia // American journal of archaeology. 2002. Vol. 106, №1. P. 1-10 : ill. (в соавторстве с И.И. Гохманом и др.).

54. М.П. Завитухина (1926-2001) [Некролог] // Сообщения ГЭ. 2003. №60. С. 249-250 : портр. (в соавторстве с Л.С. Марсадоловым).

55. Костюм и текстиль пазырыкцев Алтая: (IV-III вв. до н. э.). Новосибирск : Инфолио, 2005. 232 с. : ил.; рез. англ. Библиогр.: с. 212-221 (в соавторстве с Н.В. Полосьмак).

56. Татуировки на мумиях из Больших Пазырыкских курганов // Археология, этнография и антропология Евразии. 2005. №2. С. 48-59 : ил. (в соавторстве с С.В. Панковой).

57. Татуировки на пазырыкских мумиях: новые материалы // Эрмитажные чтения памяти Б.Б. Пиотровского : сборник докладов. СПб. : ГЭ, 2005. С. 15-26 : ил. (в соавторстве с С.В. Панковой).

58. Войлочный колпак из Второго Пазырыкского кургана // Сообщения ГЭ. 2006. №64. С. 31-35 : ил. (в соавторстве с Е.А. Чеховой).

59. Татуировки на алтайских мумиях // Природа. 2006. №3. С. 64-68 : ил. (в соавторстве с С.В. Панковой).

60. М.П. Завитухина (1926-2001) [Некролог] // Теория и практика археологических исследований. Вып. 3. Барнаул : Изд-во Алт. ун-та, 2007. С. 177-178 : портр. (в соавторстве с Л.С. Марсадоловым).

61. Die Fürstengräber der Pazyryk-Kultur. // Im Zeichen des goldenen Greifen: königräber der Skythen. (Ausstellungs: Berlin, 06.07.-01.10.2007; München, 26.10.200720.01.2008; Hamburg, 15.02.-25.05.2008). Berlin, 2007. P. 118-131.

62. Новые исследования импортных тканей из Больших Алтайских курганов // Сообщения ГЭ. 2009. №67. С. 5-21 : ил.

63. Красота, сотканная из тайн: Древнейшие в мире ковры. СПб. : Изд-во Гос. Эрмитажа, 2012. 48 с. : ил. (In brevi).

64. Скотоводы Алтая (Пазырыкская культура) в скифскую эпоху // Кочевники Евразии на пути к империи. Из собрания Государственного Эрмитажа. Каталог выставки. СПб. : Славия, 2012. С. 91-100.

65. Средневековые панцирные пластины с территории Алтая из коллекции П.К. Фролова // История и культура средневековых народов степной Евразии. Барнаул : Изд-во Алт. ун-та, 2012. С. 99-103 : ил. (в соавторстве с В.В. Горбуновым и А.А. Тишкиным).

66. Технологическая характеристика шерстяных тканей из Больших Алтайских курганов // Археологический сборник ГЭ. 2013. Вып. 39. С. 41-58 : ил.; рез. англ.

67. Фантастические звери на татуировках алтайского вождя // 250 историй про Эрмитаж: «Собранье пестрых глав...» : в 5 кн. Кн. 3. СПб. : Изд-во ГЭ, 2014. С. 98-101.

68. Изображение петуха в искусстве древнего Алтая // Археологический сборник ГЭ. 2015. Вып. 40. С. 143-156.

Составили Л.М. Всевиов, Л.С. Марсадолов, В.Б. Семёнова, Е.В. Степанова 